\title{
Social Services Will Not Touch us with a Barge Pole': Social Care Provision for Older Prisoners
}

\author{
Kate O'Hara \\ Technological University Dublin, kate.ohara@mydit.ie \\ Katrina Forsyth \\ University of Manchester; \\ Jane Senior \\ University of Manchester
}

See next page for additional authors

Follow this and additional works at: https://arrow.tudublin.ie/aaschsslarts

Part of the Sociology Commons

\section{Recommended Citation}

O'Hara, K. et al. (2015) Social Services will not Touch us with a Barge Pole': Social Care Provision for Older Prisoners, The Journal of Psychiatry \& Psychology,Vol.26, no. 2, 2015. doi:10.1080/

14789949.2014.1000938

This Article is brought to you for free and open access by the Social Sciences at ARROW@TU Dublin. It has been accepted for inclusion in Articles by an authorized administrator of ARROW@TU Dublin. For more information, please contact arrow.admin@tudublin.ie, aisling.coyne@tudublin.ie,gerard.connolly@tudublin.ie.

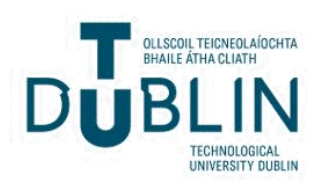




\section{Authors}

Kate O'Hara, Katrina Forsyth, Jane Senior, Caroline Stevenson, Adrian Hayes, David Challis, and Jenny Shaw 


\section{'Social Services will not touch us with a barge pole': Social care provision for older prisoners}

O'Hara, Kate.

Offender Health Research Network, University of Manchester, Manchester, UK Kateohara3m@hotmail.com

Forsyth, Katrina.

Offender Health Research Network, University of Manchester, Manchester, UK Katrina.forsyth@manchester.co.uk

Senior, Jane.

Offender Health Research Network, University of Manchester, Manchester, UK Jane.senior@manchester.ac.uk

Stevenson, Caroline.

Offender Health Research Network, University of Manchester, Manchester, UK Caroline.stevenson@manchester.ac.uk

Hayes, Adrian.

Coventry and Warwickshire Partnership NHS Trust, Warwick, UK adrianjhayes@hotmail.com

Challis, David.

School of Nursing, Midwifery and Social Work, University of Manchester, Manchester, $U K$

David.challis@macnehster.ac.uk

Shaw, Jenny.

Offender Health Research Network, University of Manchester, Manchester and Lancashire Care NHS Foundation Trust, Preston, UK

jen@jenshaw.net 


\section{'Social Services will not touch us with a barge pole': Social care provision for older prisoners}

Older prisoners are the fastest growing subgroup in the English and Welsh prison estate. Older prisoners have high levels of health and social care needs. This mixed method study involved the distribution of a questionnaire examining the availability of health and social care services for older prisoners to all prisons housing adult males in England and Wales, followed by qualitative telephone interviews with representatives from eight prisons. Over half of establishments had some contact with external social care services but reported significant difficulties in arranging care for individuals. A professional lead for older prisoners had been identified in $81 \%$ of establishments; however the value of this role to positively affect practice appeared questionable. Statutory social care was often non-existent in prison due to the lack of understanding of what it constituted and who was responsible for its provision.

Keywords: older prisoners; social care provision; unmet social needs; older prisoner lead; older prisoner policy 


\section{Introduction}

It has been well documented that the number of older prisoners is increasing rapidly across developed countries (American Civil Liberties Union, 2012; Grant, 1999; Ministry of Justice, 2004, 2014; Uzoaba, 1998). Prisoners aged 50 and over are the fastest growing sub-group within the English and Welsh prison estate, currently accounting for $12 \%$ of the prison population (Ministry of Justice, 2014). In common with older people in the community, prisoners often present multi-faceted social care needs. For example, Hayes, Burns, Turnbull, \& Shaw (2013) found that over a third of older prisoners in their UK sample had some level of functional need with regards to routine activities of daily living. Tellingly, over half of those identified as having personal care needs considered those needs to be unmet.

In July 2012, the UK government published 'Caring for our future: reforming care and support', outlining proposed reforms to adult social care in England and Wales. The document specifically recognised the current lack of clarity concerning responsibility for assessing and providing social care support to prisoners and included a pledge to develop a new framework clearly outlining where such responsibility lies when a new Care Bill comes into effect in 2015.

The aim of this research study was to understand the current provision of services, including the integration between health and social care services, for older male prisoners.

\section{Methods}

The research described below was undertaken as part of a large-scale project, funded by the National Institute for Health Research, Service Delivery and Organisation Programme (SDO- 09/H1203/47; Senior et al., 2013). The study combined mixed methods of data collection and analysis, including a scoping questionnaire distributed to the 97 prisons in England and Wales housing adult men, augmented by more in-depth semi-structured interviews in a selection of sites. The topics included in the questionnaire were drawn from the recommendations for good practice made in the Department of Health's older offender toolkit (Department of Health, 2007) and Her 
Majesty's Chief Inspector of Prison's thematic review of older prisoners (HMCIP, 2008). The questionnaire asked, about any discrete health and social care provision for older prisoners; specific training opportunities for staff; levels of engagement with external social services; and whether there was a specific lead for older prisoners.

The questionnaire was distributed to healthcare managers both electronically and by post. It was decided that healthcare managers would be best placed to provide the information required; this approach also maintained consistency across prison establishments. Seventy eight questionnaires were returned (80\%). Representatives from eight prisons were invited to take part in telephone interviews, based upon questionnaire responses identifying apparent success $(n=4)$ or profound difficulties $(n=4)$ in the facilitation of social care for prisoners. This approach was chosen to identify significant strengths and weaknesses across the prison estate. A researcher conducted thirty-two telephone interviews with a range of staff members, including healthcare staff, prison officers and managers and third sector staff. Qualitative data were analysed using the constant comparison method (Glaser, 1965), aided by the computer software package NVivo (Q S R International Ltd, 2008). An additional researcher acted as a 'peer debriefer', conducting periodical discussions with the researcher who conducted the interviews and analysis. This provided an opportunity to test emerging themes and increased the credibility of the findings (Leech \& Onwuegbuzie, 2011).

\section{Findings}

\section{Questionnaire findings}

Data were analysed by prison type (local ${ }^{1}$, open ${ }^{2}$ and training ${ }^{3}$ ). There were no statistically significant differences between prison types for any of the variables.

\footnotetext{
${ }^{1}$ A type of prison that contains those awaiting trial, convicted of short sentences, and those at the beginning of longer sentences.

${ }^{2}$ A type of prison that has no perimeter security and contain those trusted not to abscond, usually prisoners at the end of long sentences or those on very short sentences.

${ }^{3}$ A type of prison that holds only sentenced prisoners, usually transferred from local prisons.
} 
Findings revealed that specific training in the care and assessment of older people was provided to healthcare staff in less than half of the establishments $(41 \%, \mathrm{n}=32)$. Even where such training was available, only a small minority of staff had completed it. For example, such training had been completed by only eight percent $(n=135)$ of staff working in primary care and in-patient services and, similarly, only seven percent $(\mathrm{n}=$ 28) of those working in mental health services.

In nearly half of prisons surveyed $(35 \%, \mathrm{n}=27$ ) some form of peer support/buddy scheme was in operation. These schemes were most likely to be found in training prisons $(45 \%, \mathrm{n}=17)$. Over half of establishments overall $(64 \%, \mathrm{n}=50)$ had some level of contact with external social care services; proportionally, this was highest within training prisons $(71 \%, \mathrm{n}=27)$ and lowest within open prisons $(29 \%, \mathrm{n}=2)$.

A professional lead for older prisoners had been identified in $81 \%$ of establishments (n =63). However, the value of this role to positively affect practice appears questionable, given that only just over half of establishments had a written older prisoner policy $(56 \%, n=44)$. Other examples of good practice were also limited; only 53 percent $(n=$ 41) offered specific healthcare clinics for older prisoners, and a comparable proportion had established links with any specialist older adult organisations $(51 \%, \mathrm{n}=40)$. 
Table 1. Services available to older prisoners stratified by prison type

\begin{tabular}{|c|c|c|c|c|}
\hline & $\begin{array}{l}\text { Local } \\
\text { prisons } \\
n=33\end{array}$ & $\begin{array}{l}\text { Open } \\
\text { prisons } \\
n=7\end{array}$ & $\begin{array}{l}\text { Training } \\
\text { prisons } \\
\mathrm{n}=38\end{array}$ & $\begin{array}{l}\text { Total } \\
\text { Prisons } \\
\text { n = 78 }\end{array}$ \\
\hline \multicolumn{5}{|l|}{ Services for older prisoners } \\
\hline Written older prisoner care policy & $58 \%$ & $29 \%$ & $61 \%$ & $56 \%$ \\
\hline Identified lead for older prisoners & $88 \%$ & $71 \%$ & $76 \%$ & $81 \%$ \\
\hline Prisoner helper/buddy scheme & $27 \%$ & $14 \%$ & $45 \%$ & $35 \%$ \\
\hline Older prisoner clinic & $58 \%$ & $57 \%$ & $47 \%$ & $53 \%$ \\
\hline Contact with local social care services re older prisoners & $64 \%$ & $29 \%$ & $71 \%$ & $64 \%$ \\
\hline Co-ordinated approach between healthcare $\&$ social care services re older prisoners & $33 \%$ & $29 \%$ & $29 \%$ & $31 \%$ \\
\hline Sufficient communication from social services re older prisoners & $27 \%$ & $14 \%$ & $13 \%$ & $19 \%$ \\
\hline Written protocol between healthcare and social care services re older prisoners & $3 \%$ & $0 \%$ & $5 \%$ & $4 \%$ \\
\hline Contact with specialist older adult organisations & $55 \%$ & $71 \%$ & $45 \%$ & $51 \%$ \\
\hline
\end{tabular}




\section{Interview findings}

Interviewees' definitions of what actually constituted social care varied greatly. Some participants described social care need as fundamentally consisting of support with routine activities of daily living:

'It's... basic stuff really isn't it? You know, if somebody's struggling to get washed or dressed'

(Social care worker)

Others described social care in much broader terms, including support with housing, employment, and finances in their definition:

'Social care, well it's the kind of Job Centre and the Voluntary Bureau, and the Citizens' Advice Bureau, and Age UK for pensions and benefits advice'

(Third sector organisation worker)

This basic lack of agreement regarding what social care actually consists of contributes to the confusion over who is responsible for providing a range of interventions and support.

Interviewees reported that many statutory social services departments simply refused to provide assessments or care services for older people in custody. Often this was based on a view that, as a department, they were not responsible for those who were going to be released to other geographical areas. As one Disability Liaison Officer described:

'Social services will not touch us [prisons] with a barge pole.... Because they say it's not their responsibility while they're in prison'.

This refusal to engage commonly resulted in healthcare staff, or even other prisoners, being tasked to deliver social care. One care worker described how other prisoners would be left to assist their peers without adequate training to undertake such a role, and the response she had received from a prison officer when she raised concerns about this situation. 
'Oh you [Social Care Worker] shouldn't have to do that [change incontinence pads]. Just leave... we'll get the prisoners to do that.' But it was giving our knowledge and expertise over to the prisoners to deal with the situations that they were dealing with in a safe manner, because they [other prisoners] were dealing with incontinence, and not dealing with it properly. So the spread of infection could have been quite high. So passing that knowledge over to them [other prisoners] from our point of view, we thought was quite... you know, it needed to be beneficial for them, because they [prisoners] were very much left by the Prison Officers [to care for older prisoners].

\section{Discussion}

Findings from this study suggest that there is a fundamental lack of agreement surrounding the definition of what constitutes social care in a prison setting. This contributes to social care inappropriately being seen as the responsibility of healthcare staff as opposed to a wider multi-disciplinary role (HMCIP, 2008). In some instances, prisoners are providing very personal social care to older peers, often doing so with no appropriate training. There are undoubtedly some social care tasks that may be appropriately and safely carried out by other prisoners such as carrying food trays, cleaning cells and pushing wheelchairs, if adequate training and supervision is provided. However, there are legal, ethical and health implications of personal care being provided by prisoners that require further investigation, not least the issue of personal choice. Prisoners may be faced with no other practical option but to accept support with personal care from other prisoners; such a situation would simply not be permissible or considered acceptable in any analogous institutional living setting in the community, for example a care home.

The current legal framework stipulates that the primary responsibility for providing social care lies with the statutory authority where the person is 'ordinarily resident'. However guidance on the meaning of this term refers to prisoners' geographical location after release, not during incarceration (Williams, 2012). Findings from this research illustrate that the 'ordinary residence' rule is a very effective barrier to 
providing social care to older prisoners. Current practice completely fails to take into account the very fluid and geographically spread nature of the prison population, often resulting in social care not being available to older people at any time during their incarceration.

In 2008, HMCIP recommended that every establishment should identify an Older Prisoner Lead and, whilst our research illustrates that this goal has been largely met, the continued dearth of specialised services for older prisoners and lack of equivalence to community service provision suggestions that the simple identification of such a role can be meaningless. To counteract this Older Prisoner Leads require specialist training and, equally importantly, adequate dedicated time in order to be beneficial to older prisoners.

\section{Conclusion}

Our research identifies that statutorily-provided social care is often non-existent in prison, due to the lack of understanding of what it constitutes and who is responsible for its provision. Where it is available, it is frequently inappropriately provided by healthcare staff or fellow prisoners with scant or no training. The introduction of the new England and Wales Care Bill may provide a starting point to rectify this unacceptable situation. An identified and proactive social care lead in each prison, alongside comprehensive local agreements between prisons and social services, should ensure that local social services effectively co-ordinate care for all prisoners, regardless of their geographical allegiances. Additionally, the introduction of resettlement prisons ${ }^{4}$ should facilitate the housing of older prisoners in closer proximity to their planned location on discharge and, consequently, if discharge planning is effectively conducted, should assist in ensuring their social care needs are appropriately met on release from prison.

\footnotetext{
${ }^{4}$ Resettlement prisons are identified establishments which house prisoners close to the geographical area they will be living in after release in order to more effectively coordinate their discharge into the community.
} 


\section{References}

American Civil Liberties Union. (2012). At America's Expense: The Mass Incarceration of the Elderly. American Civil Liberties Union: New York.

Department of Health. (2007). A pathway to care for older offenders. A toolkit for good practice. London: Department of Health.

Glaser, B. G. (1965). The Constant Comparison Method of Qualitative Analysis. Social Problems, 12(4), 436-445.

Grant, A. (1999). Elderly Inmates: Issues for Australia. Australian Institute of Criminology Trends \& Issues in Crime and Criminal Justice, 115, 1-6.

Hayes, A., Burns, A., Turnball, P., \& Shaw, J. (2013). Social and custodial needs of older adults in prison. Age and Ageing, 0, 1-5. doi:10.1093/ageing/aft066

Her Majesty's Chief Inspector of Prisons. (2008). Older prisoners in England and Wales: a follow-up to the 2004 thematic review by HM Chief Inspector of Prisons. Retrieved March 02, 2013, from http://www.justice.gov.uk/downloads/publications/inspectoratereports/hmipris/thematic-reports-and-researchpublications/older_prisoners_thematic-rps.pdf

Leech, N. L., \& Onwuegbuzie, A. J. (2011). Beyond constant comparison qualitative data analysis: Using NVivo. School Psychology Quarterly, 26(1), 70-84.

Ministry of Justice. (2004). White paper on crime 2004: Treatment of Offenders. Retrieved June 14, 2013, from http://hakusyo1.moj.go.jp/en/50/nfm/mokuji.html

Ministry of Justice. (2014). Offender Management Caseload Statistics 2013. London: Ministry of Justice

Q S R International Ltd. (2008). NVivo 8.0 qualitative data analysis programme.

Uzoaba, J. H. E. (1998). Managing older offenders: Where do we stand? (Report No. R70). Ottawa, Ontario, Canada.

Williams, J. (2012). Social care and older prisoners. Journal of Social Work. doi:10.1177/1468017311434886 